REIS, A. H. (2020)

Exercícios de Tragosofia em tempos de Pandemia: o bode, a ovelha e o lugar da inventividade na prática do filósofo DOI: $10.31416 /$ rsdv.v8i2.47

\title{
Exercícios de Tragosofia em tempos de Pandemia: o bode, a ovelha e o lugar da inventividade na prática do filósofo
}

\author{
Tragosophy exercises in Pandemic Times: the goat, the sheep and the place of
} inventiveness in the philosophers practice

\section{REIS, Alexandre H. Doutor/Licenciado em Filosofia}

Universidade Federal do Vale do São Francisco - Campus Juazeiro. Av. Antônio C. Magalhães, 510 - Country Club, Juazeiro - BA, 48902-300 Juazeiro/BA - Brasil / Telefone: (74) 2102-7609 / E-mail: alexhreis@gmail.com

\section{RESUMO}

O presente ensaio desenvolve seu itinerário partindo de uma análise do cenário transformado pela pandemia do COVID-19, compreendendo a própria crise como uma resposta humana ao vírus. Este cenário permite reavaliar diversos elementos cotidianos e a própria ideia de reflexão filosófica, que corre sempre o risco de dar as costas para o mundo da vida. Algumas ideias fundamentais são, assim, colocadas sob análise, como a ideia de "encontro", própria do exercício filosófico e humano, sobretudo quando a razão impõe quarentena quando não há outras técnicas capazes de enfrentar a contaminação. Ao mesmo tempo em que o isolamento social é imposto como técnica de vida, a própria ideia de filosofia pode ser repensada, por exemplo, quando voltamos às escolas do helenismo que pensaram a filosofia como exercício e modo de vida. Assim, o tempo presente, em 2020, é o momento oportuno para revisões fundamentais na vida cotidiana, e a própria filosofia é convidada a se aproximar do mundo da vida. Nesta aproximação, é possível notar que as polarizações políticas presentes em nossa democracia e as rupturas entre os discursos políticos evidenciam que o uso do entendimento se cristalizou em si mesmo, como um polo autônomo que não reconhece senão a si mesmo como verdade. 0 ensaio que aqui se desenvolve redescobre, portanto, a ideia hegeliana de necessidade da filosofia, segunda a qual a razão procura juntar o que é separado pelo entendimento. No início de nossa modernidade, Hegel aponta, portanto, para a perda da ideia de conciliação no mundo ético. Este retorno a Hegel, absolutamente breve, não tem outra função senão a de mostrar a necessidade de ultrapassar a tradição, aprendendo com ela o exercício da crítica. Ao desenvolver um exame da filosofia como atividade acadêmica, Os Exercícios de Tragosofia criam metáforas explicativas que remetem às diferenças entre o bode e a ovelha, para fazer nascer provocações que exigem de nosso tempo renascimentos possíveis. É exatamente esta cisão do mundo ético que procuramos mostrar e apontar para a necessidade de ultrapassá-la. A expressão tragosofia é tomada da obra poética de Luiz Cláudio da Cruz (Marimagístico. Belo Horizonte: Literato, 2017) e desenvolvida no sentido de eleger alguns princípios fundamentais da prática filosófica pensada a partir da inventividade como princípio fundamental para a ativar a imaginação filosófica. Portanto, o ensaio examina algumas concepções de filosofia, a exemplo do estoicismo e da escolástica, e retoma algumas ideias fundamentais da tradição ocidental, como encontro, cisão do mundo ético, o eu e o outro, e desenvolve os princípios de inventividade e desobediência como fundamentos de uma tragosofia, isto é, de uma sabedoria prática que fundamente na vida do filósofo uma autenticidade que supere as cisões entre vida cotidiana e vida intelectual, entre o exercício exegético da leitura do texto filosófico e a imaginação filosófica. Tudo isso à luz do contexto atual, marcado pela pandemia do COVID-19, que se desenvolve em meio a uma crise que se estende em todos os setores da vida humana.

Palavras-chave: pandemia, mundo ético, estoicismo, COVID-19

\begin{abstract}
This essay develops its itinerary, starting from an analysis of the scenario transformed by the pandemic of COVID-19, comprising a crisis itself as a human response to the virus. This scenario allows us to evaluate several everyday elements and an idea of philosophical reflection, which always runs the risk of turning its back on the world of life. Some fundamental ideas are, therefore, put under analysis, as an idea of "encounter", a philosophical and human exercise, mainly when a reason imposes quarantine when there are no other possible contamination techniques. At the same time that social isolation is imposed as a life technique, an idea of philosophy can be compensated, for example, when we return to Hellenism schools that think about exercise philosophy and way of life. Thus, the
\end{abstract}


REIS, A. H. (2020)

Exercícios de Tragosofia em tempos de Pandemia: o bode, a ovelha e o lugar da inventividade na prática do filósofo

present time, in 2020, is the opportune time for fundamental analyzes in everyday life, and a philosophy of its own is invited to approach the world of life. In this approach, it is possible to note the political polarizations present in our democracy and the ruptures between the political discourses that show the use of understanding if crystallized in it, as an autonomous pole that does not recognize the same. The essay developed here, therefore, rediscovers an Hegelian idea of the need for philosophy, according to which the reason why the search must join or separate by understanding. At the beginning of our modernity, Hegel points, therefore, to the loss of the idea of conciliation in the ethical world. This return to Hegel, which is absolutely brief, has no other function than to show the need to go beyond tradition, learning from it or exercising criticism. When developing an examination of philosophy as an academic activity, The Exercises of Tragosophy create explanatory metaphors that refer to the differences between the code and the sheep, to give rise to provocations that show our possible renaissance rhythm. It is exactly this instance of the ethical world that will seek to show and point to a need to overcome it. A tragic expression is taken by Luiz Cláudio da Cruzs poetic work (Marimagístico. Belo Horizonte: Literatura, 2017) and developed with no sense of choosing some fundamental principles of philosophical practice thought from inventiveness as a fundamental principle to activate philosophical philosophy. Therefore, the essay examines some conceptions of philosophy, for example, stoicism and scholasticism, and takes up some fundamental ideas of western history, such as encounter, split of the ethical world, or me and another, and developing the principles of inventiveness and disobedience as fundamentals a Tragedy, that is, it is a practical practice that helps in the life of the philosopher, an authenticity that surpasses the sections between everyday life and intellectual life, between the exegetical exercise of reading the philosophical text and the philosophical reading. All this in the light of the current context, marked by the COVID-19 pandemic, which is developing in the midst of a crisis and extends to all sectors of human life.

Keywords: pandemic, ethical world, estoicism, COVID-19

\section{Introdução como Agradecimento}

A filosofia é antes de mais nada, um exercício vital no qual se constroem pensamentos e formas de vida que são, num só golpe, práticas e contemplativas. A prática do filósofo é, por certo, a atividade de pensar e neste sentido, devemos discutir constantemente o que é objeto de pensamento filosófico. "Pensar é agradecer" (HEIDEGGER, 2003, p. 216) na medida em que este exercício é sempre aprendido dentro de uma tradição. Portanto, pensar não é um ato originário que surge a partir de si, mas é sempre relacional, pois pensar é pensar alguma coisa a partir de certas condições. Pensar é uma espécie de pôr em movimento formas vitais que se desenvolvem em exercício. Mas ao se desenvolver em formas autênticas, este exercício conduz a determinadas cisões que colocarei em exame para considerar questões fundamentais neste momento em que, não apenas as forças democráticas e republicanas de nossa vida política estão sob ameaça constante, mas o nosso próprio modo de viver está sob reavaliação, devido à pandemia do novo Coronavirus Disease 2019 (COVID-19).

0 caminho a ser percorrido, neste momento, exige que coloquemos sob o exercício da crítica o nosso próprio modo de vida que sofre, não há dúvidas, modificações que persistirão ainda por um bom tempo. Este momento é assim oportuno para uma série de discussões que evocam a habilidade de pensar. A ideia mesma de crise está associada a ideia de crítica, ambas as palavras possuem a mesma raiz: o verbo grego krinō. A krisis é a ação de distinguir, de decidir e de tomar decisões e a ideia mesma de crítica envolve a noção de distinguir, examinar e questionar (MALHADAS, DEZOTTI, NEVES, 2008, p. 94). Não há crise sem a capacidade de colocar em questão as coisas que estão aí. Neste sentido, quando as forças não-humanas modificam o estado de coisas humanas, as mudanças maiores, a crise ela mesma, é resultado de escolhas e decisões que tomamos diante de tais forças. 
REIS, A. H. (2020)

Exercícios de Tragosofia em tempos de Pandemia: o bode, a ovelha e o lugar da inventividade na prática do filósofo

Não há pandemia sem que se considere a presença do vírus como conveniência de mudanças necessárias para lidar com o seu próprio agente causador, sobretudo quando não se tem a ciência necessária para produzir técnicas de superar o estado de coisas proposto pelo vírus. Assim, quando a razão humana propõe o "isolamento social” como mecanismo mais eficaz de não contaminação, os efeitos das mudanças no modo de vida que resultam na crise estão diretamente ligados à tomada de decisões humanas e menos ligadas ao próprio agente natural. A crise não é, portanto, produto do vírus, mas da necessidade de modificar o modo de vida para lidar com o vírus.

Isto posto, o itinerário do ensaio que se desenha à nossa frente pode ser descrito da seguinte maneira: primeiro, proponho um olhar para o atual momento da humanidade, submetida a uma pandemia devastadora dos modos de vida social, econômica, política, etc., que praticávamos até aqui, para então me voltar para a ocupação da filosofia, o que equivale a perguntar pela prática e pelo ofício do filósofo quando o estado de coisas se encontra em crise. Uma volta aos estoicos será inevitável. Em seguida, o que será colocado em exame é a própria ideia de encontro, entendendo esta ideia tal como foi praticada pelos gregos no sentido de Sympósium, esta palavra grega que os tradutores de Platão traduzem por Banquete, e que exige o diálogo vivo como prática filosófica. Vencida esta etapa, caberá examinar a ideia de necessidade da filosofia, expressa em momentos de crise sob a necessidade de se examinar, em verdade, as rupturas entre o eu e o outro sob a violência ou incapacidade de afirmação de um nós diante da pluralidade de elementos identitários. Por fim, o presente ensaio colocará sob exame a noção de tragosofia (que até o presente momento carece de esclarecimentos e desenvolvimentos) para apontar alguns princípios fundamentais e possíveis para a prática filosófica no mundo em crise e no mundo pós-pandêmico. A exigência tragosófica é precisamente a exigência de tornar a filosofia viva, cultivada a partir do solo em que se pisa, por exemplo, levando-se em conta as forças sertânicas que abrigam o filósofo do Nordeste brasileiro. Estas mesmas exigências impelem a reflexão filosófica a tomar como objeto o próprio tempo pandêmico.

O impacto do Coronavírus nos sistemas de saúde mundiais, quando ainda não há medicações eficazes e muito menos vacinas, tem exigido medidas que restringem as relações sociais efetivas e promovem modificações e o uso mais presente de tecnologias de comunicação. A pandemia do Coronavírus mostra diferentes realidades dentro de um mesmo país que resultam em variações no índice de mortalidade pela Severe Acute Respiratory Syndrome Coronavirus 2, devido à presença ou ausência de leitos hospitalares, respiradores e outros suprimentos demandados (cf. Ferguson et al. 2020). Esta evidência mostra que as técnicas humanas podem reduzir a mortalidade da doença e que, em determinados momentos oportunos, a ausência de tais técnicas conduz à morte inelutavelmente. Portanto, o vírus e sua mortalidade não têm ligações apenas com questões biológicas e tecnológicas, envolve diretamente decisões políticas e visões de mundo sociais, que demandam investimento em tecnologias hospitalares e igualmente em tecnologias sociais. Tanto a filosofia quanto as ciências humanas são fundamentais no enfrentamento da pandemia, exatamente porque as decisões políticas demandam certos esclarecimentos que não passam pela pesquisa de laboratório, mas envolvem diretamente modos de vida que são, neste momento, alterados.

0 ensaio que aqui se desenvolve como exercício de pensamento envolve questões que passam 
REIS, A. H. (2020)

Exercícios de Tragosofia em tempos de Pandemia: o bode, a ovelha e o lugar da inventividade na prática do filósofo

longe de propor soluções sociais e políticas, mas inscreve a necessidade de uma meditação acerca do sentido do modo de vida que conduz a uma necessidade da filosofia em tempos de crise. Esta necessidade evoca, ela mesma, questões sociais e políticas, que são, portanto, consequências do exercício de pensar a própria maneira de viver o tempo presente e que exige de si reflexões sobre modificações possíveis e necessárias.

\section{Pandemia e a persistência dos estoicos}

A primeira exigência da pandemia, antes de chegar ao domínio da vida doméstica, é a sabedoria de tomar decisões do ponto de vista médico e político. Médico porque é preciso compreender a dimensão da doença, e político porque as decisões afetam diretamente a vida das pessoas. Mas esta primeira exigência de sabedoria em tomar decisões afere uma vontade política e uma capacidade médica. Do ponto de vista político, é um teste de tolerância ideológica e de resistência à ignorância brutal do uso da força no momento em que se exige a audição de pontos de vistas distintos. Esta mesma necessidade de audição é posta para a medicina, que é, em verdade, uma técnica, uma arte: a medicina precisa ouvir a ciência. Mas, claro, a pandemia promove modificações em todos os domínios da atividade humana. Do ponto de vista religioso, a pandemia provocada pelo COVID-19 evoca antigos sentimentos de fé que, em muitas pessoas, desenvolve-se pela real aproximação da morte possível e antecipada. Portanto, a pandemia coloca a todos questões profundas para a existência humana, na medida em que as pessoas são afetadas pela realidade que persiste. Até mesmo os negacionistas movimentam-se em torno do que pretendem negar.

A organização da vida cotidiana, em níveis planetários, sofre modificações que conduzem a revisões no modo de vida e que estimulam tomadas de opinião: possivelmente, para as gerações atuais, a necessidade de assumir um posicionamento acerca de questões das quais não se tem conhecimento, muitas, em verdade, que exigem conhecimentos especializados (acerca de prescrição de medicamentos e protocolos clínicos), nunca foi tão persistente. Com as escolas fechadas, a vida doméstica ganha outros contornos com a presença dos estudantes, das mais diversas faixas etárias. Tomar decisões sobre reabertura do comércio em tempo desconexo da reabertura das escolas traz questões difíceis, que exigem tomadas de opiniões. Em verdade, nada do que aprendemos até aqui dá conta da reestruturação da vida cotidiana. Alimentar-se e manter-se saudável é essencial em tempos de pandemia, mas o tempo gasto com o trabalho, remoto ou presencial, mostra que pouco sabemos acerca da nossa própria vida cotidiana e doméstica, por mais que estejamos nela. As reações individuais e coletivas são diversas, mas mostram que muitas emoções estão em jogo quando decisões difíceis precisam ser tomadas e opiniões assumidas, sobretudo quando discursos antagônicos se mostram na vida política.

Quando os governos dão ouvidos à razão científica mais esclarecida, que reconhece a deficiência tecnológica para lidar com a pandemia, a técnica recomendável exige a um só tempo distanciamento e solidariedade. Ser solidário é assumir a si mesmo como um elemento fundamental no jogo da transmissão do vírus. É esta ação individual que requer o exercício do conjunto humano. Schopenhauer compreendia as interações comunitárias como um difícil exercício de encontrar a distância correta, como acontece com o dilema do porco-espinho, que precisa se aproximar de seus 
REIS, A. H. (2020)

Exercícios de Tragosofia em tempos de Pandemia: o bode, a ovelha e o lugar da inventividade na prática do filósofo

outros para aquecer-se do frio, mas não pode se aproximar demais para não se ferir e ferir com seus espinhos. Os porcos-espinhos, nesta fábula contada pelo filósofo alemão, indo de um lado para o outro, e sofrendo o mal do frio e o mal do espinho, encontraram, enfim, "a distância média na qual puderam resistir melhor” (SCHOPENHAUER, 1988, pp. 559-560) É este distanciamento ideal que se impõe como imperativo na reabertura da vida no mundo pós-pandêmico. E este aspecto social, político em sentido próprio, exige, repito, que cada ação individual coloque a si própria como objeto de reflexão e objeto de questão. Permitam-me as palavras de Schopenhauer, em outra obra, para que possamos pensar uma questão que exige reflexões para a vida cotidiana:

\begin{abstract}
É preciso viver com apropriado conhecimento sobre o curso das coisas no mundo. Todas as vezes que alguém perde o controle, ou sucumbe aos golpes da infelicidade, ou se entrega à cólera, ou se desencoraja, mostra justamente que concebe as coisas de maneira diferente do que esperava, logo que estava errado e não conhecia o mundo nem a vida, não sabia como a natureza inanimada, pelo acaso, assim como a natureza animada, por intenções opostas e também por crueldade, cruza a cada passo a vontade individual. (SCHOPENHAUER, 2005, p. 144)
\end{abstract}

Schopenhauer, com estas palavras da seção 16 de seu livro capital, $O$ mundo como vontade $e$ representação, evoca a própria filosofia como um modo de vida, tipicamente como faziam as escolas gregas da era do helenismo. É esta questão que gostaria de colocar na mesa de discussões. Qual é o objetivo da filosofia? Ora, a resposta destas escolas, a exemplo do estoicismo, é muito clara: responder à pergunta fundamental: como devo viver? Ora, a filosofia somente pôde se voltar para a vida neste período e poderá fazê-lo em qualquer tempo, porque viver expõe o ser vivente a uma série de problemas persistentes. Não são apenas as questões matemáticas, cósmicas e ontológicas que colocam problemas para a ocupação filosófica, como pode pensar o leitor da história da filosofia. Paixões, medo, doenças, morte, a busca pelo poder, as traições, os governos injustos, a vida sexual, tudo isto perturba o pensamento e impele a uma reflexão filosófica constante pela serenidade da vida. A filosofia tornou-se neste período pós-Aristóteles e pré-Agostinho, uma forma de vida terapêutica que se dedicou a combater e a reduzir os males da vida, sem nenhuma pretensão de removê-los. Era a isto que chamavam amor fati.

A filosofia antiga foi assim marcada pelo exercício espiritual, ou seja, uma atividade prática que não fazia a cisão entre as atividades intelectuais e vida cotidiana, de modo a transformar no filósofo e em sua existência, o modo de viver e enxergar as coisas. Submetido às condições impostas pela crise da pandemia, e, repito, compreendo a crise como a resposta humana ao vírus, somos levados a compreender na importância do estoicismo a filosofia como exercício vital. No caso dos estoicos, construiu-se uma filosofia da aceitação precisamente porque o conhecimento do curso do mundo, para lembrar a citação de Schopenhauer, importa mais do que a construção de teorias. Este princípio da aceitação, longe de ser uma resignação, é uma atividade diante do destino. Epicteto disse: Há coisas que dependem de nós e há coisas que não dependem de nós. A observância da resposta ao vírus, dentro das técnicas atuais, promove uma crise profunda que deve ser observada: distanciarse do outro, cumprir regras de higiene, cuidar de si, tudo isto tem como resultado um cuidado do outro, que é mínimo, mas cuja extensão pode ser ampliada. 0 que não depende de nós, são ao mesmo 
REIS, A. H. (2020)

Exercícios de Tragosofia em tempos de Pandemia: o bode, a ovelha e o lugar da inventividade na prática do filósofo

tempo o vírus que se impõe violentamente e a ignorância dos governos que não promovem planos de superação da crise, mas lutam para a defesa idiossincrática que resulta numa luta contra as próprias instituições que compõem a República.

Os estoicos enfrentariam a atual pandemia, ou suportariam a crise contra o vírus, a partir das quatro virtudes que julgavam essenciais. Quando me refiro aos estoicos procuro suprimir as peculiaridades de cada escola propriamente para enxergar os seus pontos em comum, pois são muitas as diferenças. Antes de falar destas quatro virtudes, as exigências de rigor impõem que eu justifique melhor estas supressões necessárias à sua definição. Além disso, seria pedante pressupor que o leitor tenha a obrigação de conhecer estas escolas. Permitam-me, antes, portanto, apenas algumas considerações gerais e didáticas.

O chamado estoicismo antigo deu início à escola estoica entre os gregos, com Zenão de Cítio, seu "fundador". Esta escola teve figuras importantes, como Aríston de Quíos, Crisipo e Cleanto, entre outros filósofos diversos. Este período se estende até o século III ou II a. C., a depender do modo como se lê as obras de Boeto (ou Boezo) de Sídon, que se conta também entre os peripatéticos e de Arquimedo de Tarso.

Por que esta escola filosófica ficou conhecida por estoicismo? A Stoá é um elemento arquitetônico formado por um corredor e colunas, presente de modo usual na entrada de prédios públicos, na Antiguidade greco-romana. Havia, assim, muitas stoai nas cidades gregas. Stoá pode ser traduzido por Pórtico, ou mesmo Hall ou Colunata. O nome da escola filosófica veio devido ao Pórtico

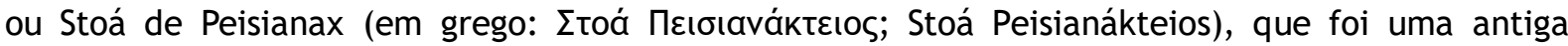
edificação na Agorá (Aүopá, praça pública) de Atenas, construída durante o século V a.C.. Este pórtico fica no lado norte da Agorá, e era o lugar onde Zenão de Cítio realizava suas reuniões regulares e suas palestras, por volta do ano 300 a.C. Estrangeiro em Atenas, Zenão era impedido de comprar uma casa ou um prédio para construir sua escola. Em torno dele, juntaram-se muitos discípulos e outros filósofos e por se reunirem na Stoá foram chamados $\Sigma \tau$ twïkós, stoikós, ou numa tradução para o nosso português, "filósofos do pórtico."

Ficou conhecido na História da Filosofia como estoicismo médio as escolas dos pensadores Panécio e Possidônio, sobretudo. Panécio foi mestre da escola de Stoá, e mitigou a prevalência da virtude para a felicidade: também meios materiais moderados, a saúde e os deveres são fundamentais para uma vida feliz. Possidônio deu continuidade ao trabalho de Panécio, sucedendo-o na direção da escola. Algumas outras figuras têm mais importância histórica que filosófica, como é o caso de Hecatue de Rodes, discípulo de Panécio, que ao se interessar menos pelas questões da lógica e da física (própria do estoicismo antigo), voltou-se para questões morais e exercerá forte influência no terceiro período do estoicismo.

Por fim, o estoicismo novo. Os principais pensadores: Sêneca (que se matou sob as ordens de Nero no ano 65 da era cristã), Caio Musônio Rufo (25-95 d.C.), Epiteto (50-135 d.C.) que foi aluno de Musônio Rufo, Hiérocles (100-150 d.C), de quem se descobriu em 1901 um papiro intitulado Elementos de Ética e, por fim, Marco Aurélio (121-180 d.C), o imperador-filósofo de Roma, tido como um governante muito bem-sucedido, justo e culto, que nos deixou diversas obras. Houve, é claro, muitos outros nomes, mas cito apenas aqueles que tive o prazer de estudar por conta própria após os meus 
REIS, A. H. (2020)

Exercícios de Tragosofia em tempos de Pandemia: o bode, a ovelha e o lugar da inventividade na prática do filósofo

anos de formação e que recomendo ao leitor. Os estoicos não interessam aos professores de filosofia, de modo geral, e os alunos saem dos cursos de graduação sem examinar suas obras.

Os estoicos possuem, em seus diversos períodos e sob a diversidade de seus representantes, diferenças fundamentais. Mas é possível, didaticamente, suplantar as diferenças e compreender seus interesses comuns: física, lógica e ética. Tanto a física quanto a lógica são exercitadas na compreensão diária do mundo, embora seja possível reconstruir teoricamente as contribuições dos estoicos dentro destas disciplinas. A este respeito, remeto o amigo leitor ao livro bastante acessível de Pierre Hadot, O que é Filosofia Antiga? (p. 189 e seguintes).

A ética estoica é fundada em uma ideia muito esquecida nas éticas contemporâneas, mas fundamental para as éticas antigas: a noção de virtude. Hoje fala-se mais em deveres do que em virtudes (cf. REIS, 2018, página 121-128). Os estoicos apregoavam a equivalência da existência com a realidade, ou seja, a equivalência da vida com a natureza, visto que a realidade é a expressão mais exaltada da razão e a natureza, ao seu julgamento, é racional. Assim, o imperativo ético é viver na radical aceitação do destino, no combate contra as forças da paixão que produzem a intranquilidade. Adequar-se ao destino, aceitá-lo, é aceitar a racionalidade do mundo e a presença da justiça como força racional na existência do mundo. 0 mal é o resultado deste desvio, desta não adequação, é, portanto, oriundo dos vícios, da ausência das virtudes, do entregar-se às paixões sem ter em mãos o seu controle, do que decorre o desequilíbrio e a destruição moral de si mesmo. Diferentemente do que poderia parecer, os estoicos construíram uma profunda crítica política e social e, portanto, suas doutrinas não caminham para uma resignação diante dos vícios da sociedade. A equivalência das atitudes ao real é um equilíbrio com o que é racional, e as sociedades, sobretudo a sociedade romana daquela época, é marcada pela corrupção e pelos vícios. Os estoicos do chamado novo estoicismo, os estoicos romanos, propuseram reformas sociais e políticas fundadas em ideias de cosmopolitismo e de sabedoria prática. No fundo, o estoicismo estabeleceu-se, entre os romanos, como ética, como uma concepção de vida que para além da compreensão teórica e expressão retórica se firmou como atitude diante da vida e diante da morte. Mas estas propostas éticas partem de homens como Sêneca ou Marco Aurélio, que são políticos, no sentido republicano. Não é verdade que o projeto estoico se reduz a elevar o homem à condição de sábio, na verdade, este é um ponto essencial, mas igualmente essencial, e não posso deixar de dizê-lo, é o caráter público da ética estoica, sobretudo com os pensadores romanos, que viveram a política e exerceram cargos públicos. A atitude diante da morte e o que esta atitude pode representar de sabedoria e o resistir diante das tormentas da vida são ensinamentos públicos, que devem se estender até o homem comum.

As ideias de Sêneca, de Cícero e de Marco Aurélio, sobretudo, têm se mantido populares ainda hoje, em pleno início da década de 2020 , quando pandemias abatem as sociedades mundiais, como mostra o vasto interesse editorial e comercial de seus livros. Notem que os governantes devem praticar a virtude, o seu exemplo, ou seja, o exercício público da virtude, deve educar os cidadãos. Sob o governo que o Brasil possui hoje, seria necessário inverter a ideia: podemos aprender eticamente com o presidente da República, com seus ministros e suas equipes não se espelhando em seus vícios, que são praticados publicamente.

As ideias de uma atitude virtuosa diante dos mares revoltos da vida faziam parte do imaginário 
REIS, A. H. (2020)

Exercícios de Tragosofia em tempos de Pandemia: o bode, a ovelha e o lugar da inventividade na prática do filósofo

da nobreza romana, e elas provavelmente mostram a coragem e as escolhas de muitos personagens da política romana diante da morte. Como mostrei em outro lugar, o ideal ético do estoicismo pode ser compreendido na postura serena de encarar o abismo (REIS, 2020, cap. 1). Voltemos agora, à questão que me interessa: as quatro virtudes estoicas que podem nos ajudar diante da pandemia e da crise atual.

A primeira virtude é a sabedoria, que implica correlacionar os acontecimentos provindos da natureza com a razão. Implica, do ponto de vista do exercício prático, em acolher os acontecimentos com calma e serenidade. Considerando que a razão é natural e a natureza é racional, as técnicas que promovem a crise, como a quarentena, o distanciamento social, a higiene necessária e até mesmo o lockdown, quando imposto pelas condições já em termos de desastre, devem ser aceitas tanto pela força necessária de resposta que dão ao vírus, quanto pela independência da presença do vírus em relação a nossa vontade individual. A razão estoica compreendeu, na prática da sabedoria, que em situações com esta não é sábio procurar um responsável, culpa-lo e amaldiçoá-lo, como as acusações do ministro das relações exteriores da nossa República. Psicologicamente, este tipo de reação implica na expressão do pânico.

A segunda virtude estoica que deve ser lembrada é precisamente a justiça. A justiça foi elevada, por exemplo na Ética de Aristóteles (2001, livro V) como a mais importante das virtudes, sem a qual sequer outras virtudes são possíveis, precisamente porque é a própria justiça que define a virtude como justa medida. Na atividade prática dos estoicos, em tempos de crise, a virtude da justiça deve ser praticada na interação com as outras pessoas, no encontro do distanciamento ideal, como os porcos-espinhos de Schopenhauer. A terceira virtude é a moderação. Desacostumado a ficar consigo mesma, a pessoa descobre o quão difícil é ficar a sós, ficar consigo, ou com o outro que habita a mesma casa. E diante disso, lança-se para fora em um uso abusivo de redes sociais ou, quando tem condições, lança-se às compras desnecessárias, virtuais ou presenciais, que dão vasão a este desejo de sair de si. A virtude da moderação é, portanto, necessária para moderar os prazeres, isso vale para a comida e a bebida e outras substâncias. Esses excessos, se não estavam presentes antes da quarentena, revelam o pânico de ceder aos impulsos e ao seu império. A moderação dos prazeres é a virtude que encontramos também, e com a mesma relevância, em diversas outras escolas gregas, entre os platônicos, os aristotélicos, os epicuristas, etc.

A quarta virtude estoica necessária para sobreviver à pandemia é a coragem. Tomar decisões que implicam em efeitos desagradáveis, respeitar o bem comum e a presença do outro, implicam coragem, esta virtude necessária e condição de possibilidade para a mudança de hábitos. Se juntarmos essas quatro virtudes teremos diante de nós uma determinação no modo de vida que implica precisamente no que estas escolas antigas chamaram de felicidade. A felicidade, vale lembrar, é uma atividade, um exercício da virtude, que permite um distanciamento do que promove os sofrimentos, como o destempero e os vícios.

Aí estão, neste breve retorno às escolas do helenismo, privilegiando o estoicismo, as raízes da filosofia pensada como modo de vida. É precisamente este tipo de compreensão filosófica que revela a força de suas reflexões para momentos de crise que imperam nossa vontade sob os atuais revezes. Estamos testemunhando, com o nosso sofrimento e sobretudo com o modo como lidamos 
REIS, A. H. (2020)

Exercícios de Tragosofia em tempos de Pandemia: o bode, a ovelha e o lugar da inventividade na prática do filósofo

com esse sofrimento, modificações profundas no modo de nossa existência coletiva: globalização, ultraliberalismo e baixa prioridade nos assuntos públicos, individualismo, tudo isto sairá profundamente alterado desta pandemia. Como serão estas alterações é difícil prever, porque existem forças reativas na vida política que impelem a conservações de elementos que deveriam ser revistos, quando pensamos no bem comum e na vida comum das Repúblicas.

Dizendo de modo mais radical, mas este modo fará parte da minha análise e proposta de uma tragosofia, mais adiante, deveríamos aproveitar este momento para destruir diversas condições de vida para dar lugar ao princípio da inventividade que, do ponto de vista ético e político, isto é, aliado ao princípio da solidariedade, poderia fazer parir novos mundos. Ora, se estamos afundados no caos, econômico, humanitário, social, não seria desejável que, ao sair da pandemia, pudéssemos viver uma realidade mais ajustada à natureza de nossa racionalidade? Existe, no entanto, como acabo de dizer, forças reativas que nos colocam sob um forte risco de encontrar na saída do túnel, senão o mesmo mundo de antes, um mundo ainda pior, porque as condições materiais de todos nós estarão, por certo, em piores condições.

Crises recentes, provocadas como reações as epidemias por SARS e por H1N1, não foram capazes de trazer para os costumes, melhores adaptações às necessidades de higiene, equipamentos de proteção hospitalar ou investimentos proporcionais aos estragos em saúde pública. 0 que sabíamos depois da SARS e da H1N1? O que sabíamos ao lembrar da devastadora gripe espanhola? Sabíamos que em quanto sociedade, não tínhamos condições de enfrentamento de novas epidemias. Mas este saber não se converteu em uma preparação para o inesperado. Se o COVID-19 trará modificações estruturais no modo de governar o país e nas nossas próprias vidas, por nós mesmos, é muito incerto diante da ignorância que se impõem por forças políticas que, ao ascenderem ao poder lançando-se sob as molas do ódio à esquerda, conseguiram destruir a própria direita em nosso jogo democrático.

Mas, o que realmente importa, do ponto de vista filosófico, é aprender com a pandemia a lidar consigo mesmo. No século XVII, um filósofo francês escrevia:

\footnotetext{
Quando me pus, algumas vezes, a considerar as diversas agitações dos homens e os perigos e as penas a que se expõem, na corte, na guerra, de onde nascem tantas querelas, paixões, empresas ousadas e muitas vezes más, eu disse muitas vezes que toda a infelicidade dos homens provém de uma só coisa, que é não saberem ficar em repouso num quarto." (PASCAL, 1966, artigo XXI, 2)
}

Viajar, entregar-se ao trabalho, encontrar os amigos, as redes sociais, dedicar-se aos negócios, os bares, as férias, sair da direita para a esquerda, todas estas ocupações são uma espécie de distanciamento de si mesmo. A quarentena imposta pela crise, compreendida por sua vez como resposta ao vírus, não nos revela precisamente o que Pascal observou nas sociedades de sua época? A crise permite-nos ao menos formular a pergunta sobre o que é essencial em nosso modo de vida. A ideia mesma de crise (krisis), repito, é a ação de distinguir, decidir e tomar decisões, a crítica, por seu turno, envolve esta mesma capacidade de distinção, exame e questionamento. As redes sociais revelam ao menos dois tipos de dependência: o olhar para o outro e o olhar do outro. Sair de si mesmo, e olhar para a vida alheia, pode revelar uma ausência de qualidade da vida de si, que importa tomar como oportunidade para dedicar-se a melhorar o próprio modo de vida. Por outro lado, quando se 
REIS, A. H. (2020)

Exercícios de Tragosofia em tempos de Pandemia: o bode, a ovelha e o lugar da inventividade na prática do filósofo

espera o olhar do outro, nas redes sociais, espera-se, em verdade, cobrir a própria vaidade que revela a ausência de coragem de cultivar a si próprio. É preciso coragem para produzir cisões necessárias a um aperfeiçoamento de si.

\section{O encontro como elemento vital da atividade filosófica}

Quando uma forma particular de filosofia surge, ela não nasce senão da originalidade viva do espírito que nela estabeleceu, através de suas experiências, as condições possíveis de seu vir a ser. Mas, segundo penso, é preciso acrescentar um outro elemento sem o qual a filosofia não é possível: uma forma particular de cisão sem a qual teríamos apenas a ideia de continuidade. A ideia mesma de um ensaio evidencia a necessidade do exercício no qual o pensamento se desenvolve e através do qual encontra força argumentativa para estabelecer seus pontos de apoio e combater suas imperfeições. 0 ensaio é sempre uma preparação e como tal, estabelece a esperança de um dia deixar de sê-lo ao encontrar uma forma mais amadurecida de se mostrar e de se reestabelecer. Portanto, formas particulares de filosofia estão sempre vinculadas a formas específicas de vida que encontram em si mesmas a matéria do pensamento e, ao desenvolverem-se na linguagem e como linguagem, combatem o que foi aprendido e apreendido na tradição, daí a noção de cisão necessária para o estabelecimento de si e através da qual deve proceder. Esta é uma primeira forma de cisão que considero afirmativa de si, mas há uma segunda noção da qual falarei mais adiante, uma cisão negativa, que submeterei à análise.

As relações entre o pensamento e o modo de vida ocuparam as filosofias gregas de modo geral, como vimos a pouco no caso dos estoicos. Através de Xenofontes (1999) e de Platão (1902), apreendemos que Sócrates, ao dedicar-se a modo peculiar de exercitar a filosofia, esforçou-se por compreendê-la de um modo absolutamente prático no qual a originalidade viva do espírito não se afastasse do exercício da virtude até o ponto de cisão que desse autonomia às formas puras de pensamento. Tomo por formas puras de pensamento a independência do uso do entendimento em relação ao mundo da experiência, mais ou menos ao modo dos filósofos racionalistas modernos. Uma das ideias fundamentais do exercício filosófico levado a cabo por Sócrates, como modo de vida, é a prática do encontro. Depois que Platão e Aristóteles desenvolveram suas obras, tanto as suas escolas, - Liceu e a Academia (com a exceção das gestões de diretores que privilegiaram a matemática), quanto as escolas que nasceram no período do helenismo, mantiveram o ideal socrático de desenvolver a filosofia como um modo de vida. Para somar ao que já disse acerca do estoicismo, evoco as palavras de Plutarco (1984: p. 202): “A maior parte das pessoas imagina que a filosofia consiste em discutir do alto de uma tribuna e dar cursos sobre textos. Mas o que escapa totalmente a essas pessoas é a filosofia ininterrupta que se vê exercer a cada dia de uma maneira perfeitamente igual a si mesma." A filosofia é um exercício que se desenvolve no cotidiano. Nas salas de aula, no exercício de leitura e exame das obras, travamos contato com produtos que muitas vezes são frutos destes exercícios. Neste sentido, é possível repensar as direções que temos dado à filosofia em nossa vida intelectual. Uma destas formas de trazer a filosofia para a prática da vida cotidiana está precisamente na ideia de encontro, sobre a qual são necessárias algumas explicações. 
REIS, A. H. (2020)

Exercícios de Tragosofia em tempos de Pandemia: o bode, a ovelha e o lugar da inventividade na prática do filósofo

Já há alguns anos, vem se desenvolvendo no interior do Nordeste um simpósio de filosofia intitulado Sertão Filosófico, cuja terceira edição ocorreu na cidade de Ouricuri, sob o tema "Filosofia sem fronteiras." Pretendo falar da ideia de encontro partindo deste encontro. Este simpósio possui ao menos dois significados fundamentais: primeiro, permite o encontro daqueles que se dedicam à filosofia no sertão do nosso Nordeste; e todo encontro de filósofos possui o gesto fundamental da filosofia: o exercício da amizade, que vem a ser a crítica no sentido antigo de exame de nossa própria tarefa. Filosofar exige o encontro: é preciso colocar-se diante do outro, expor o pensamento ao outro e ouvir-lhe de bom grado o que nossa própria consciência não é capaz de dizer a si mesma. Portanto, este primeiro significado representa aquela prática do sympósium dos antigos, que é preciso resgatar. Talvez eu não consiga expressar de modo fundamental, mas sabemos que em nossos tempos atuais, quando a própria política invade o espaço doméstico e divide famílias inteiras, na polarização aparente de opiniões opostas, existe um trabalho de negação do outro, de esquecimento do outro, ou de redução do outro a uma aparente diferença que só pode ser afirmada no desaparecimento do trabalho do espírito. Em tempos assim, estranhos, perdemos a capacidade de ver no outro, no diferente, traços de identidade que nos permitem a síntese do nós. 0 uso das redes sociais, em tempos de pandemia, parece conduzir as pessoas a um exercício de combate do outro, de combate do ponto de vista do outro e até mesmo, como expõe constantemente o entorno da família que hoje governa o país, a redução do outro à ideia de inimigo.

Estou insistindo neste primeiro significado fundamental do Terceiro Encontro do Sertão Filosófico para chamar a atenção para este ponto: há hoje uma necessidade da filosofia. E entendo que esta necessidade da filosofia esteja evidentemente na reconstrução do outro. Historicamente, esta categoria do outro é uma conquista relativamente recente. Mesmo o amor (eros) em Platão (2013) é apenas um “intermediário dinâmico" (metaksú) que conduz a alma na ascensão para a contemplação da Ideia do Belo. E mesmo a rejeição de Aristóteles do idealismo platônico, não desprende o amigo, ou a amizade perfeita, de uma subordinação às exigências da contemplação: na ética de Aristóteles (2001: 1170b), no logos da vida teorética, o amigo vê o amigo "como um outro eu." Toda a concepção clássica de vida contemplativa, biós theorētikós, fortemente presente também nos jardins do estoicismo, atenua a necessidade do outro: daí a ideia do universalismo do logos; as exigências do ócio (skolē) e da tranquilidade (hēsychia) e o imperativo estoico do aperfeiçoamento individual. Por isso, o estoicismo é uma filosofia ideal para o enfrentamento do isolamento social necessário para a manutenção da crise atual. Lembrando que a crise, resultado de nossas escolhas, é a resposta que conseguimos dar à pandemia provocada pelo COVID-19. A solidão é tipicamente uma marca do ideal de sabedoria. No fim da Antiguidade, a solidão do sábio encontra expressão na fuga para o Uno de Plotino, uma espécie de expressão mística do logos grego. Na atualidade, já é muito se despedir das redes sociais.

Do ponto de vista filosófico, a grande contribuição do cristianismo foi precisamente a introdução da categoria do outro na expressão do próximo (plēsíon), conforme pode ser verificado em Lucas X, 25-27. Portanto, na Antiguidade o outro é introduzido sob a ideia de reconhecimento e de amor. Na antropologia filosófica caberá a Tomás de Aquino colocar o problema do outro como um dos seus temas centrais, além de Pascal e São Francisco de Sales. Mas de algum modo, no racionalismo 
REIS, A. H. (2020)

Exercícios de Tragosofia em tempos de Pandemia: o bode, a ovelha e o lugar da inventividade na prática do filósofo

moderno, sobretudo a partir de Descartes a noção de sujeito e de autonomia novamente jogam o outro no esquecimento. Caberá a Hegel fazer reaparecer o outro na linha da dialética das alienações: a consciência será consciência-de-si somente se passar pelo momento do reconhecimento (Anerkennung) do outro. Há dois momentos fundamentais na Fenomenologia do Espírito: a dialética do senhor e do escravo e a dialética da cultura e da linguagem, capítulos IV e VI, respectivamente.

Para não me estender muito nas reflexões desta ideia, segundo a qual há hoje uma necessidade da filosofia que se manifesta na necessidade de reconstrução do outro, permitam-me, rapidamente lembrar um filósofo não muito estudado em nossos cursos de filosofia, mas que talvez tenha aprofundado mais que qualquer outro, essa ideia de encontro ao examinar o fenômeno do diálogo e da relação pessoal do eu com o outro: refiro-me ao vienense Martin Buber (1878-1965), e aqui sugiro duas obras fundamentais: Eu e Tu, um ensaio escrito em 1923 sobre o problema da existência, publicado em português pela editora Moraes e pela Centauro e o livro Sobre Comunidade, traduzido nos anos 80 pela Perspectiva. Eis uma de suas questões que nos fazem pensar, e que aqui procuro sintetizar com a seguinte pergunta: a cisão entre pessoa e coisa não conduz o mundo dos objetos a um destino avesso à comunidade das pessoas, de tal modo que a reunião ou comunhão do nós não se torna uma "diversão mística" que nos retira de um empenho histórico? Buber constrói uma filosofia do diálogo, mas não se trata de um diálogo entre dois falantes tão somente. Ele evoca para esse logo de diá-logo, não aquele logos grego que conhecemos bem em nossas formações de graduação, mas sobretudo a noção de ação. Judeu que era, Buber compreende logos como palavra, como linguagem, e diferentemente de um aspecto intelectual, a palavra coloca o homem em comunicação, de tal modo que a função propriamente humana é sempre uma relação: a relação com o isto ou aquilo, ou seja, com o mundo dos objetos, e a relação com o tu, que estrutura o mundo da participação pessoal. Não vivemos apenas na relação com o tu, e é preciso, segundo Buber, que o filósofo esteja aberto para pensar a relação com o isto, de modo a pensar a si mesmo como aberto. Claro que o isto não se refere apenas ao mundo dos objetos materiais não-humanos. A própria ideia de outro implica a ideia de isto, ou seja, que eu também seja tomado por objeto, por alteridade. Neste jogo dialógico, a vocação humana se revela no próprio fenômeno do diálogo.

A cisão entre pessoa e coisa corre o risco de tornar o mundo das coisas contrário ao destino dos homens, ou seja, ele, o mundo das coisas, pode tornar-se guia das ações humanas, o que pode ser hoje mais facilmente compreendido do que na primeira metade do século passado. As coisas guiam os homens. E esta cisão corre também o risco de tornar a comunhão dos homens uma reunião ahistórica, ou seja, um encontro de filósofos no sertão deve implicar a situação das coisas que nos circundam: exige consciência histórica, mesmo que façamos o exercício de suspender o juízo, momentaneamente.

Em tempos de quarentena, como este enfrentamento que a humanidade experimenta neste início dos anos de 2020, torna-se oportuno repensar o valor da comunidade. Na ausência das relações com o outro, na ausência do encontro efetivo das consciências que vivenciam o isolamento social, é a própria ideia de comunidade que pode ser reavaliada. Martin Buber concebe a comunidade num sentido oposto ao atual estado de coisas, quando aquilo que talvez possamos definir como bolsonarismo, isto é, a supressão das diferenças, torna-se uma realidade persistente. A comunidade 
REIS, A. H. (2020)

Exercícios de Tragosofia em tempos de Pandemia: o bode, a ovelha e o lugar da inventividade na prática do filósofo

é a vida liberta de limites e conceitos de tal forma que não há distinções entre comunidade e vida. Viver é viver a comunidade. Permitam-me dar a palavra ao próprio Buber (1987, p. 34): “toda vida nasce de comunidades e aspira a comunidades. Ela é fim e fonte de vida. Vida e comunidade são os dois lados de um mesmo ser."

E aqui chego ao fim deste primeiro aspecto fundamental que faço questão de ressaltar: o Terceiro Encontro do Sertão Filosófico é uma reunião, um reconhecimento, um sympósium, em que a filosofia é exercitada em sua prática fundamental. Trata-se, portanto de uma prática, de um exercício para o qual estamos não apenas dispostos, mas estamos fundamentalmente destinados. Por destino, entendo aqui um caminho que se impõe a cada um de nós, em nossas mais variadas experiências, e o qual não podemos simplesmente não percorrer. Não podemos escolher outra vocação, mesmo que tenhamos outros empregos. Viver a filosofia no sertão é vivê-la envolvido pelo próprio contexto em que é exercitada. Mesmo em tempos de quarentena: pois aqui, na escrita, na leitura, também estamos afinal, reunidos e em sympósium.

Mas eu dizia: o encontro possui dois significados fundamentais. Além do exercício filosófico da amizade, do encontro, da crítica, existe a questão que nos traz até aqui. Este aqui não se refere apenas ao encontro efetivo que ocorreu em Ouricuri, em outubro de 2019. Aqui é quando a leitura e a escrita se encontram. Aqui é este agora, e este agora é esta reunião entre o leitor e o texto escrito. O Encontro em si mesmo é fundamental, mas o que podemos fazer quando nos reunimos? 0 que nos reúne aqui neste momento? Não é apenas a necessidade da filosofia, a necessidade da reconstrução do outro, é sobretudo o exercício da liberdade de pensar. Um encontro de filósofos no sertão pernambucano quando uma certa política desabilita a filosofia e as ciências humanas por não "gerarem valor agregado às suas atividades" é exatamente isso: o reconhecimento da necessidade da liberdade de pensar. A liberdade é o próprio valor fundamental e o próprio fundamento da atividade humana: não é a filosofia que é atacada pelos governos não-democráticos, é a própria liberdade. Sei que se trata de um conceito polissêmico, mas não vou evocar este ou aquele significado de liberdade: pensem, neste momento, nos diversos sentidos da palavra liberdade e em suas variadas ressonâncias. As liberdades, permitam-me, portanto, o plural, dão a este Encontro, este agora, o seu segundo significado fundamental. E a minha contribuição com este ensaio vai desaguar exatamente em uma determinada concepção de liberdade que, segundo penso, é não apenas possível, mas necessária no momento histórico que estamos a viver.

$\mathrm{Na}$ aurora de nossa Modernidade, quando a ciência experimental vislumbrou a si mesma em desenvolvimento, quando a técnica pretendeu-se unida à ciência, e lá se vão exatos 400 anos da primeira edição do Novo Organum, de Francis Bacon, quando, pois, a Modernidade amanheceu, a razão instrumental e a inteligência humana pretenderam ocupar o lugar da própria razão, que levou inelutavelmente a uma cisão profunda entre ciência e filosofia. É da própria cisão que nasce a necessidade da filosofia. Quando temos discursos opostos que se fixam em si mesmos, pretendendo ser a própria razão, temos, em verdade, uma falsa razão que precisa ser combatida através de uma análise que suplante a fixidez de tal oposição e que seja capaz de se desenvolver em novas sínteses. Hegel (1979, p. 14), percebeu bem esta cisão, quando escreveu: 
REIS, A. H. (2020)

Exercícios de Tragosofia em tempos de Pandemia: o bode, a ovelha e o lugar da inventividade na prática do filósofo

A necessidade da filosofia surge quando o poder de unificação desaparece da vida dos homens e os opostos perderam a sua relação viva e ação recíproca, adquirindo autonomia. A necessidade (Bedürfniss) é uma contingência, mas é necessário (notwendig) suprassumir, na cisão dada, a contraposição da subjetividade e da objetividade tornadas fixas, e apreender (begreifen) o sertornado (Gewordensein) do mundo intelectual e real como um devir, e o seu ser como produtos, como um produzir.

A cisão pode ser percebida facilmente na cultura, e promove rupturas e a perda da capacidade de uma visão englobante. Que se tome por exemplo a divisão de ministérios em setores que isolam seu objeto, como ocorre com o meio ambiente, até o nível de separá-lo de sua própria efetividade, como se pudesse ser tomado pelo interesse de um determinado grupo que tem pretensões de explorálo, mesmo que isso custe a sua própria existência. No display em acrílico da mesa do Ministério do Meio Ambiente lê-se: "Sales" e não me refiro ao nome do ministro (em maio de 2020) que se escreve com dois L's.

Mas estas cisões estão presentes também na vida cotidiana: elas expressam a incapacidade de ver qualquer possibilidade de reconciliação. Portanto, a ideia de cisão, expressa em sua negatividade, indica a impossibilidade de uma visão que englobe, que adiciona à contradição o impulso necessário para superá-la.

Mas há, em sentido positivo, cisões necessárias, rupturas importantes. Volto, inelutavelmente, à máxima de Heidegger, pensar é agradecer. Devo, portanto, propor-me a pensar o significado do que seria uma tragosofia. E eu agradeço, não somente à tradição, porque se podemos criticar a tradição é exatamente porque ela nos ensinou a crítica, mas agradeço a generosidade do amigo leitor por promover este encontro. A leitura é um encontro, e o encontro já supera inicialmente cisões que devem ser ultrapassadas. Esta generosidade expressa não somente a disposição para o exercício da filosofia, mas de modo especial, expressa as virtudes que podemos pensar e praticar durante a pandemia do COVID-19.

\section{Exercícios de Tragosofia: algumas proposições ou provocações}

É comum o proceder a partir da definição quando se encara o desafio de compreender um determinado conceito ou uma determinada noção com a qual se vai trabalhar. Mas não esperem neste momento uma definição de tragosofia. A definição pouco importa: uma compreensão que caiba no espaço do conceito deixa de fora o mundo da vida, e é exatamente este um dos pontos que devemos reestabelecer quando paramos, em quarentena, para exercitar a filosofia: alargar a filosofia até que englobe a existência do filósofo. Neste sentido, a filosofia não pode ser entendida como exercício intelectual, tão somente. E a literatura está aí para nos ensinar a pensar também o homem dentro de suas experiências e de suas possibilidades. Quantas vezes, ao ler um romance, uma novela, um conto, não nos apropriamos das experiências dos personagens... e quantas vezes, ao ler as obras de nossos filósofos, não deixamos de fora as nossas próprias experiências.

Para iniciar, permitam-me proceder como Martin Buber (1991, p. 693), a quem cito uma vez mais: "Tomo a quem me ouve pela mão e o encaminho à janela. Abro a janela e aponto para o que está lá fora. Não tenho nenhuma doutrina, mas mantenho uma conversação". 
REIS, A. H. (2020)

Exercícios de Tragosofia em tempos de Pandemia: o bode, a ovelha e o lugar da inventividade na prática do filósofo

A região do sertão nordestino engloba muitas cidades, além de Petrolina e Juazeiro nas quais, em tempos não pandêmicos, transito diariamente. Esta região engloba Ouricuri, em que ocorreu o Terceiro Encontro do Sertão Filosófico. Cidade que conheço bem até os sertões da Quixaba, em Parnamirim, o pequeno vilarejo de onde vem a família de Dona Espedita, mãe de minha esposa. Gostaria de transportar a imaginação do amigo leitor para o interior deste sertão. Abro em comunidade com o leitor, portanto, a janela de nosso sertão para ver ali fora, na caatinga selvagem, o animal exótico que de tão familiar parece nativo dessas terras: o bode, este animal simbólico que atravessa a história de tantos povos desde épocas muito remotas. 0 bode caminha livremente às margens das rodovias, ignorando as cercas humanas, exigindo a atenção dos motoristas. Quando nos aventuramos a adentrar a caatinga, na profundidade em que esperamos encontrar animais selvagens (quem sabe avistar uma suçuarana!), lá ouvimos o berro do animal. Ele está em todo lugar. No prato diário do sertanejo, nos cordéis, na literatura, nas canções e nas festas populares. Mas é precisamente o bode que estava na origem das tragédias gregas, não nos esqueçamos! E no Livro de Levítico encontramos igualmente o animal que é ali sacrificado na epifania!

Mas não quero ir longe. E nem poderia, para colocar o outro em risco e pôr-me em risco, servindo-me de elo na corrente do Covid-19. Olhemos a janela de nosso sertão: o bode não obedece às ordens do pastor. 0 sertanejo chama as ovelhas, que vêm dóceis ao seu encontro. Por sorte, adaptaram-se ao calor e não têm tanta lã a thes cobrir o corpo, como no sul. Mas o sertanejo tem de ir até onde o bode está. Ele não atende ao chamado. Aprendi a admirar as cercas de gravetos trançados na vertical, a que alguns sertanejos chamam de faxina. São cercas tradicionais, que mal permitem a passagem do ar, tão rentes estão dispostos os gravetos. Mas o sertanejo sabe que o bode não cumprirá o acordo territorial, que é próprio dos humanos. Que cerca dá conta de conter o bode? Este animal simbólico habituou-se a voltar no finzinho da tarde ao seu lugar de repouso, junto à tapera do sertanejo, mas isso depois de errar livremente pela caatinga.

Há diferenças fundamentais entre o bode e a ovelha das quais podemos tirar algumas lições para pensar o mundo pós-pandêmico. Se ainda formos capazes de virtudes, podemos redesenhar um mundo novo, ao menos em nossas vidas particulares, das quais emanam forças poderosas para a vida social. Que diferenças são essas?

O bode desobedece. E haverá forças reativas que não medirão esforços para impor o mundo pré-pandêmico. A ovelha atende ao chamado. E seguirá as vozes do poder que impõe as regras da ignorância, sobretudo aquela prática bolsonarista de reduzir a diferença à inimizade. 0 bode sobressalta-se diante das amarras. A ovelha aquieta-se. 0 bode é o animal da rebeldia. A ovelha da submissão. $O$ bode predomina no Antigo Testamento. A ovelha, no Novo. Por que motivos ele foi deixado de lado diante do Bom Pastor? O bode vai aonde quer ir. A ovelha segue as ordens do pastor. $O$ bode é resistência. A ovelha complacência. É o bode que liga o sertão dos cordelistas à Grécia dos tragediógrafos. Este é um ponto que deve ainda ser meditado, que merece uma atenção especial.

Entre os gregos, o bode é o animal amigo das crianças. Ele aparece em um vaso ático que representa a festa de Cóes, pertencente ao Walters Art Gallery, em Baltimore. Este jarro representa as crianças depois da morte. Brincam alegremente com o animal: uma vai montada no bode enquanto outra the oferece um cacho de uvas. É já uma representação própria do culto de Dioniso. Este jarro 
REIS, A. H. (2020)

Exercícios de Tragosofia em tempos de Pandemia: o bode, a ovelha e o lugar da inventividade na prática do filósofo

aparece nos estudos de Carl Kerényi (2002, p. 274) sobre Dioniso quando o estudioso evidencia uma série de elementos a partir das escavações da ilha de Creta para mostrar que inicialmente não se sacrificava um bode ao deus do teatro, mas sim touros nas Grandes Dionisíacas, permanecendo o bode como o elemento das festas dionisíacas mais próximo do humano. 0 poeta ditirâmbico do qual nasce o poeta trágico canta a alegria de viver e a primavera a partir da liberdade do bode, este símbolo da alegria, da fertilidade e da plenitude da existência. A palavra que dará nome ao novo gênero poético, marcado pelo drama, pela representação das ações, que aparece no final do século VI e predomina ao longo de todo o século V a.C., é precisamente tragédia, ou seja, uma ode (oédia) ao bode (tragos). Notem que a palavra tragédia significa literalmente uma ode, ou um hino, um canto, concernente ao bode, o animal que representa Dioniso.

A partir destas primeiras observações, chego à primeira proposição de nosso exercício de tragosofia. Ela diz respeito a uma certa desobediência que penso ser necessária à liberdade de pensar. Permitam-me deixá-la clara.

Todos nós, que estudamos, pesquisamos, vivemos e lecionamos a filosofia escolhemos uns cinco ou seis pensadores com os quais trabalhamos e dos quais esforçamo-nos para compreender em profundidade seus escritos. De modo mais aprofundado, geralmente, não dominamos mais do que isto, uns cinco ou seis autores. Dentre estes, um em especial guia o nosso trabalho, via de regra. Assim, esforçamo-nos para escrever um trabalho de final de curso, uma dissertação de mestrado ou uma tese de doutorado acerca de um pensador, com o qual estamos dispostos a trabalhar. Eu por exemplo, para não citar experiência alheia, realizei uma série de trabalhos sobre Nietzsche na graduação em filosofia na UFMG, quando participei do programa do MEC, o PET, Programa de Educação Tutorial, que na minha época chamava-se Programa Especial de Treinamento e era vinculado a CAPES. Entre o segundo período do meu curso e o oitavo, escrevi uns cinco ou seis artigos ou comunicações sobre Nietzsche, e um projeto de mestrado, que foi desenvolvido logo após a graduação. Ao terminar o mestrado, eu já estava com o projeto de doutorado estruturado abordando novamente a obra de Nietzsche. Geralmente, este é o destino do estudante que vai para a pós-graduação: ele torna-se especialista em um pensador. Mas não podemos esperar muito: a obra de um filósofo é geralmente tão densa e complexa, que é preciso dedicar toda uma vida a sua compreensão, quando se busca profundidade. Uma vida dedicada a estudar o pensamento de um filósofo! Nada contra, é esse o nosso destino. E é aqui que elaboro a primeira proposição da tragosofia: é preciso não entrar em discórdia com o filósofo que aprendemos a amar, mas é preciso se preparar para a discórdia do mestre que assumimos como guia. Neste sentido, a sabedoria do bode é exatamente não seguir as ordens do pastor. Estudar Nietzsche durante muitos anos me ensinou a deixar Nietzsche de lado: não fui fazer o doutorado em filosofia na UFMG logo após terminar o mestrado, quando eu já tinha o projeto pronto, revisado, criticado, e definido junto a minha orientadora. Ao invés, fui dedicar-me a arte de lecionar, fui viver, escrever, ler literatura, ler os filósofos que havia deixado para trás, a exemplo dos estoicos. Mais tarde, quando fiz meu doutorado, treze anos depois de terminar o mestrado, Nietzsche ocupou metade de um capítulo acerca do Esclarecimento, e ele me serviu mais como objeto de pensamento do que objeto a ser fidedignamente examinado em uma exegese filosófica.

A primeira proposição da tragosofia é, portanto, a necessidade de um parricídio. É preciso 
REIS, A. H. (2020)

Exercícios de Tragosofia em tempos de Pandemia: o bode, a ovelha e o lugar da inventividade na prática do filósofo

que o filósofo aprenda a pensar, não apenas a ler, interpretar, construir longos comentários exegéticos. A sabedoria sertaneja nos mostra que errar pela caatinga selvagem não significa estar perdido ou "ariado": mesmo o mais arisco dos bodes sempre volta para repousar próximo da casa. O bode mantém a amizade com o sertanejo: ele não the obedece exatamente para manter-se amigo. A ovelha não é amiga, ela é ingênua. Neste sentido, a postura que devemos assumir com nossos mestres, nossos guias, deve ser guiada por um esforço de compreensão, de entendimento, mas esta primeira postura deve ser suplantada pela independência no pensamento, e para que isto ocorra, é preciso ter a ousadia de pensar por si mesmo, de arriscar fazer filosofia e o mais fundamental: a ousadia de vivê-la. E neste sentido, precisamos do mundo, da cultura e principalmente, não precisamos de uma identidade filosófica com a marca d'água de um grande mestre. Durante a quarentena, podemos parar, examinar, e colocar a nós mesmos em questão. Duvidar de si, duvidar de tudo que cresceu e serviu de nutrição em pasto alheio, depois, é claro, de experimentar profundamente deste pasto.

A segunda proposição que gostaria de levar ao amigo leitor refere-se a uma abertura necessária para o mundo. Neste sentido, é preciso que tenhamos senso histórico e que, assim como o bode, mantenhamo-nos abertos para o mundo. Entrar no mundo da filosofia nos coloca sob muitos riscos. Referi-me há pouco a este risco de perder a si mesmo na imensidão da obra de um pensador ou uma pensadora que aprendemos a amar. Dar assentimento a um pensador ou a uma pensadora que se torna nosso mestre ou mestra é um exercício necessário, mas arriscado: somos conduzidos a pensar como ele ou ela e a perder a nossa inventividade. Somos levados a pensar que o filósofo ou a filósofa é tão grande e nós, seus leitores ou exegetas, tão pequenos, que nos acomodamos neste lugar. Além deste risco primeiro, existe um segundo risco, o de nos apartarmos do mundo da vida, do mundo da cidade e de seus problemas: de nos tornarmos animais fechados em apriscos que nos protegem da agitação do cotidiano. A sabedoria do bode nos ensina a coragem: é preciso abrir-se ao mundo, é preciso admitir a existência do mundo, onde está presente o outro, esta categoria que corre novamente o risco de desaparecer em nosso mundo. A quarentena é um momento de aprofundar a si mesmo, suportar-se no quarto, e preparar a saída, o encontro, e a vivência da comunidade.

Tragosofia: aqui não acrescento nada mais do que a palavra nos diz: ela se deixa traduzir por sabedoria do bode, exige que nós assassinemos o nosso a priori, como diz o poeta e filósofo trágico, Luiz Cláudio da Cruz (que assina o livro Marimagístico, da editora Literato com o pseudônimo Devir). Foi este filósofo-poeta que sugeriu a expressão tragosofia ainda em nossos anos de formação, no curso de filosofia da UFMG, entre 1997 e o ano 2000. E este a priori pode ser entendido tanto no sentido da filosofia transcendental de Kant, ou seja, como elementos próprios da mente que antecedem a experiência e the dão a configuração que conhecemos, ou pode ser entendido no sentido de nossa formação filosófica, de todo o conhecimento que aprendemos em nossa trajetória de estudos e que podem nos levar a dois caminhos possíveis: ou o que aprendemos ao estudar filosofia nos ajuda a pensar filosoficamente nossa existência e o mundo, com seus elementos políticos, jurídicos, costumeiros, econômicos, etc., ou o que aprendemos ao estudar filosofia nos rouba completamente a espontaneidade de pensar até o ponto de extinguirmos completamente a nossa inventividade.

O que resta após o assassinato do a priori? "Assassinei meu a priori e mergulhei no abismo", diz o poeta Devir. E é precisamente este abismo a possibilidade da inventividade! 
REIS, A. H. (2020)

Exercícios de Tragosofia em tempos de Pandemia: o bode, a ovelha e o lugar da inventividade na prática do filósofo

Talvez o mais trágico problema da filosofia esteja na dificuldade que nós, filósofos, temos em conciliar as demandas intelectuais e as demandas afetivas de nossa vida cotidiana, onde muito é exigido de nós, que neste espaço somos amigos, pais, filhos, professores, alunos, vizinhos, consumidores, empregados e também somos responsáveis pela nossa liberdade. A pandemia pelo COVID-19 é um espelho no qual é possível ver a si mesmo, desde que não se perca o olhar nos vícios das redes sociais: no olhar o outro e no desejo do olhar do outro, de modo persistente. É aí, até onde consigo ver, que a filosofia fracassa, ao recusar como objeto de filosofia também as contradições da vida cotidiana, que são, afinal de contas, a base de nossa existência. 0 filósofo deve transfigurar as coisas, o mundo do isto, para lembrar novamente a expressão de Martin Buber, em um mundo pleno de sentido, de tal modo que haja prazer em viver quando a penumbra da vida nos convida a uma saída racional. Quando a solidão e o isolamento nos convidam ao desespero, ao pânico, e à voluntariedade da morte, devemos não apenas tomar a obra dos filósofos e dos pensadores como objeto de exame, devemos ter a coragem de transformar o cotidiano em objeto de filosofia. No mundo pós-pandêmico, a vida cotidiana estará mais presente, e a presença sempre foi um dos temas mais persistentes da reflexão filosófica.

Estes exercícios de tragosofia devem ser compreendidos pelo amigo leitor apenas como um convite a uma crítica de si mesmos, pois nossos mestres sempre estarão incumbidos de nos apresentar as críticas da cultura, da economia, da política, dos costumes, da religião, ou mesmo a crítica do eu, essa noção que elevada ao nível de categoria torna-se tão vazia que não merece senão o que damos a ela: um exame intelectual. A tragosofia talvez seja mais pertinente aos poetas, aos músicos e aos literatos, pois eles ainda preservam a inventividade ou mesmo fazem da inventividade o seu ofício. Mas não se trata de nós e eles! Espero que a filosofia possa se tornar para nós, que habitamos o sertão e podemos pensar o sertão, exatamente um exercício de tragosofia, e assim também nós, filósofos, estaremos juntos aos poetas e escritores exercitando a inventividade, esta qualidade necessária e que certamente está presente nos grandes filósofos que escolhemos seguir. Se assim conseguirmos, a filosofia trágica ou a tragosofia nada mais será que uma postura inventiva de confrontar nossos mestres, ou ao menos de não ser ovelha diante daqueles que têm nos ensinado a arte de pensar.

O outro, ou para recuperar a noção antiga de próximo, é hoje mais objeto de ódio do que a possibilidade do reconhecimento. Mas independente de nossa posição política, outro é o diferente diante do qual é possível a afirmação de si. Carecemos deste reconhecimento. E existem inimigos da filosofia que pretendem destruir o reconhecimento da diferença. Os governos preferem os decretos aos projetos de lei, exatamente para evitar a figura do outro que exige diálogo e debate. A política voltou a ser a arte de fazer combater amigos e inimigos, como preconizou Carl Schmitt, em seu famigerado escrito de 1932: "Pois bem, a distinção política específica, aquela a que podem reconduzir-se todas as ações e motivos políticos, é a distinção entre amigo e inimigo.” (SCHMITT, 2006, p. 56). À parte toda a força teórica das análises de Schmitt, sabemos que a sua posição contrária às democracias the assegurará uma cadeira como ministro na Alemanha de Hitler.

A filosofia é resistência, e nós, filósofos a exercitá-la no sertão nordestino, devemos deixar claro que o exercício de pensar livremente é o maior valor agregado que a educação pode produzir: um valor que não se submete à própria necessidade de subsistência; que não se submete à arte da 
REIS, A. H. (2020)

Exercícios de Tragosofia em tempos de Pandemia: o bode, a ovelha e o lugar da inventividade na prática do filósofo

técnica, nem pode ser vendido ou comprado como mercadoria, em cursos online ofertados pela internet. E penso que nós, pensadores do sertão, estamos com a faca e o queijo na mão para exercitar a inventividade e liberdade próprias da tragosofia, num mundo que deseja apenas ovelhas para governar. No mundo pós-pandêmico, estaremos novamente em encontros presenciais. E ao amigo leitor, lembro com Guimarães Rosa (2019, p. 260), que o sertão não é uma região geográfica, que não deva the causar estranhamento, caso não esteja no sertão... “O sertão é o sozinho! (...) o sertão é dentro da gente!"

\section{BIBLIOGRAFIA:}

ARISTÓTELES, Ética a Nicômacos, tradução de Mário da Gama Kury, São Paulo: editora da Unb, 2001. BUBER, M. Eu e tu. Introdução e Tradução: Newton Aquiles Von Zuben. 2. ed. São Paulo: Moraes, 1977. BUBER, M. Sobre comunidade. São Paulo: Perspectiva, 1987. (Coleção Debates). FRIEDMAN, M. Martin Buber: the life of dialogue. London: Routledge and Kegan Paul Limited, 1955.

BUBER Martin. Replies to my Critics. In: SCHILPP, P. A. ; FRIEDMAN, M. (Orgs). The Philosophy of Martin Buber. La Salle/Ill.: Open Court, 1991. (The Library of Living Philosophers, v.12), p. 693.

DEVIR [Luiz Cláudio da Cruz]. Marimagístico. Belo Horizonte: Literato, 2017.

FERGUSON, N., Laydon, D., Nedjati Gilani, G., Imai, N., Ainslie, K., Baguelin, M., ... Ghani, A. (2020). Report 9: impact of non-pharmaceutical interventions (NPIs) to reduce COVID19 mortality and healthcare demand. http://dx.doi.org/10.25561/77482.

HADOT, Pierre, O que é filosofia antiga? São Paulo: Layola, 1999.

HEIDEGGER. "A essência da linguagem" in. A caminho da linguagem. Tradução de Marcia de Sá Cavalcante Schuback. Petrópolis: Vozes, o Francisco, 2003.

HEGEL, G. W. F. Jenaer kritische Schriften (I), Differenz des Fichteschen und Schellingschen Systems der Philosophie, Felix Maneiner Verlag, Hamburg, 1979, p. 10-15.

KERÉNYI, Karl. Dioniso, imagem arquetípica da vida indestrutível, página 274, da editora Odysseus) PASCAL, B. Pensamentos (Pensées). Milliet, Sérgio (trad. e org.) \& Des Granges, Ch. M. (introdução e notas) Rio de Janeiro : Tecnoprint Gráfica S.A. 1966.

PLATÃO, O banquete, Bauru/SP: edipro, 2013.

PLATO, Apology of Socrates and Crito, texto grego e notas de Louis Dyer, Boston, Published by Ginn \& Company, 1902. O livro está disponível em https: / / tinyurl.com/y9byfdb4.

PLUTARCO, "Si la politique est l'affaire des Vieillards" in. CEuvres Morales, Tomo XI, 1re partie Traités 49-51 edição e tradução para o francês de Marcel Cuvigny, Paris: Belles-Lettres, 1984.

REIS, Alexandre H. Os Jardins da Academia, Curitiba: editora Appris, 2018.

REIS, Alexandre H. História do Suicídio, Livro I. Variações Antigas e o Domínio do Cristianismo. Belo Horizonte: Páginas Editora, 2020.

ROSA, Guimarães. Grande Sertão: Veredas. São Paulo, Cia das Letras, 2019.

SCHMITT, Carl, El concepto de lo político, Madrid: Alianza Editoral, 2006.

SCHOPENHAUER, Arthur. Parerga und Paralipomena. Zurique: Haffmans, 2 vols, 1988.

SCHOPENHAUER, Arthur. 0 mundo como vontade e como representação, tradução, apresentação, notas e índices de Jair Barboza. -São Paulo: Editora UNESP, 2005.

XENOFONTES. Apologia de Sócrates. São Paulo: Abril Cultural, 1999 (Coleção Os Pensadores). 